\section{A singularidade brasileira}

Jessé SOUZA. A modernização seletiva: uma reinterpretação do dilema brasileiro. Brasília, Editora da Universidade de Brasília, 2000. 276 páginas.

\section{Leonardo Avritzer}

O processo de formação e profissionalização das ciências sociais no Brasil gerou um paradoxo em termos das teorias disponíveis de explicação da especificidade nacional. Por um lado, no primeiro período das ciências sociais brasileiras, surgiu um conjunto de teorias de natureza mais ensaística, pouco sofisticadas do ponto de vista heurístico, que escolhiam algum aspecto da formação social brasileira - a presença do Estado ou o privatismo - e tentavam propor, com base nesse elemento, um modelo analítico para o entendimento do país. É assim que podemos entender o surgimento de alguns ensaios que se tornaram referência básica para a compreensão do Brasil, como Os donos do poder, de Raymundo Faoro, ou Raizes do Brasil, de Sérgio Buarque de Hollanda. A partir dos anos 60, as ciências sociais brasileiras entraram em acelerado processo de profissionalização, que levou à aplicação mais minuciosa dos modelos analíticos disponíveis à realidade brasileira. Desse processo de profissionalização surgiram o que nós poderíamos chamar de teorias de médio alcance que se preocuparam em explicar alguns aspectos da sociedade brasileira, como o corporativismo, a cidadania, os partidos políticos, o sindicalismo e a organização do Estado. No entanto, ao tentarmos adquirir uma perspectiva de longo prazo do processo de formação e consolidação das ciências sociais no Brasil, notamos uma lacuna: poucas foram as obras produzidas durante o período recente de profissionalização das ciências sociais no país que propuseram uma explicação geral acerca das características constitutivas da sociedade brasileira.

A modernização seletiva: uma interpretação do dilema brasileiro, de Jessé Souza, professor da Universidade de Brasília, vem preencher essa lacuna. Seu autor realiza um empreendimento bastante difícil: por um lado, resgata para a análise da sociedade brasileira a contribuição de diversos autores, entre eles Weber, Elias, Habermas e Charles Taylor. Cada autor, em especial Weber e Taylor, é resgatado na sua versão mais sofisticada. No caso de Weber, Jessé Souza rompe com as análises que limitam a contribuição do cientista social alemão a tipologias acerca da evolução do Estado patrimonial, operando com dois elementos adicionais que se vão mostrar decisivos para a análise do Brasil: a articulação entre idéias e interesses e a procura dos assim chamados estratos condutores, isso é, aqueles grupos sociais ou intelectuais capazes de transportar certas idéias ou visões de mundo para a realidade.

Jessé Souza utiliza ambas as idéias para criticar uma concepção bastante difundida da formação do Brasil: a da influência do iberismo. O autor argumenta, baseando-se em Weber, "que existe uma íntima imbricação entre idéias, práticas e instituições sociais", isso é, que não é possível pensar em idéias sem os seus estratos condutores correspondentes, e não é possível comparar tradições culturais sem pensar nas instituições em operação nos diferentes contextos. Assim, falar em iberismo na formação do Brasil sem analisar as nossas estruturas institucionais seria esquecer que a escravidão, a instituição total do nosso processo de formação como nação, foi uma instituição, na melhor das hipóteses, marginal no contexto de formação do Estado português.

Jessé de Souza associa esse insight, decorrente da sua interpretação de Weber, com um conceito importante da obra de Charles Taylor, um autor pouco trabalhado até agora no Brasil: o conceito de autenticidade. Charles Taylor, em seu livro The politics of recognition, resgata o conceito de autenticidade no romantismo alemão, mostrando a sua centralidade na passagem de uma sociedade hierarquizada para uma sociedade igualitária e democrática. Para Taylor, o conceito de autenticidade rompe com as identidades socialmente atribuídas e salienta as identidades geradas internamente que nos permitem reconhecer tanto a nós mesmos quanto aos outros. Jessé Souza resgata o elemento da autenticidade em Taylor para articulá-lo à sua análise sobre o processo de formação do Brasil com o intuito de mostrar que nós construímos no 
Brasil uma sociologia da inautenticidade, isso é, uma abordagem sociológica que articula o iberismo com uma comparação superficial entre o Brasil e os Estados Unidos, desprezando a variedade dentro da modernidade ocidental e não levando suficientemente em consideração os elementos específicos da formação brasileira. São esses elementos que Jessé Souza, inspirado em Taylor, procurará resgatar ao propor uma explicação alternativa sobre a formação do Brasil.

A segunda parte de A modernização seletiva é dedicada a criticar as interpretações disponíveis sobre o Brasil e a propor uma explicação alternativa. Jessé Souza critica Sérgio Buarque, Raymundo Faoro e Roberto Da Matta, mostrando que todos os três se localizariam no interior de uma mesma matriz de pensamento, matriz essa cujo elemento central seria o iberismo. Para Souza, Sérgio Buarque de Hollanda seria o fundador dessa matriz explicativa de acordo com a qual Portugal, devido à sua inserção marginal, tanto do ponto de vista geográfico quanto do ponto de vista cultural, no mundo europeu, teria dado origem a uma variante em relação aos principais elementos da cultura européia moderna: a impessoalidade, a igualdade e as demais formas horizontais de relações interpessoais. Para Hollanda, o Brasil estaria em continuidade direta com tal tradição: "[...] no caso brasileiro, a verdade, por menos sedutora que possa parecer a alguns de nossos patriotas, é a que ainda nos associa à península ibérica, a Portugal [...] Podemos dizer que de lá nos veio a forma atual da nossa cultura; o resto foi matéria que se sujeitou mal ou bem a essa forma." ( in Souza, p. 164).

Essa matriz também organizaria o pensamento de Faoro. O argumento que perpassa Os donos do poder é o de que "o Brasil herda a forma de exercício do poder político de Portugal. Como em Sérgio Buarque de Hollanda, a herança ibérica que finca fundas raízes em nossa sociedade passa a ser responsável por nossa relação exterior e inautêntica com a modernidade." (p. 168). Para Jessé Souza, ambos os autores poderiam ser enquadrados em uma categoria que ele denomina de culturalismo atávico. Ao desvincularem cultura e dinâmica institucional, eles não conseguiriam oferecer uma explicação plausível sobre como certos traços cul- turais lograram se tornar valores e normas dominantes na sociedade brasileira.

A parte final do livro é dedicada a uma análise do que o autor denomina a singularidade cultural brasileira. Jessé Souza irá articular essa singularidade a partir de uma reinterpretação bastante criativa de um aspecto da obra de Gilberto Freyre: a forma específica de organização da escravidão e da esfera privada no Brasil. Souza busca em Freyre uma passagem pouco destacada pelos seus comentaristas, que é a da importância da forma moura de organização da escravidão no Brasil, uma forma que incluiu a poligamia, a família estendida e a possibilidade de reconhecimento dos filhos ilegítimos: "os portugueses [...] assim que se estabeleceram no Brasil começaram a anexar ao seu sistema de organização agrária de economia e de família uma dissimulada imitação da poligamia, permitida pela adoção legal, pelo pai cristão, quando esse incluía em seu testamento, os filhos naturais ou ilegítimos, resultantes de mães índias e de escravas negras. Filhos que, nesses testamentos, eram socialmente iguais, ou quase iguais, aos filhos legítimos." (in Souza, p. 225). Jessé Souza mostra as conseqüências desse fenômeno na formação da nação brasileira, uma formação na qual a distância do Estado torna a família a unidade básica da colonização e, ao mesmo tempo, cria um tipo de sociedade cuja gênese poderia ser explicada por determinadas distorções nas relações pessoais de nível primário. O patriarcalismo brasileiro teria gerado uma sociedade na qual "[...] não existem limites à autoridade pessoal do senhor de terras e de escravos. Não existe justiça superior a ele, como em Portugal era o caso da justiça da igreja [...] não existia também poder policial independente que lhe pudesse exigir o cumprimento de contrato [...] last but not least [não havia] poder moral independente, posto que a capela era uma mera extensão da casa -grande." (p. 230). Toda a possibilidade de ascensão social nesse tipo de sociedade estaria ligada à possibilidade, nunca garantida, mas sempre presente, de identificação do patriarca com seus filhos ilegítimos ou naturais.

O fato de a possibilidade de ascensão social dos mestiços estar ligada à sua identificação com os valores e os interesses do opressor constitui, para 
Jessé Souza, o elemento capaz de explicar a singularidade brasileira. Tal possibilidade cria um estrato social cujas atitudes serão centrais no processo de modernização da nossa sociedade: "[...] o enorme número de mestiços e de filhos ilegítimos de senhores e de padres, indivíduos de status intermediários, quase sempre assumindo as funções de escravo doméstico ou agregado da família, de qualquer modo quase sempre mais ou menos deslocado do mundo de posições polares como são as do senhor e escravo, encontra agora uma possibilidade nova de ascensão e mobilidade social [...] Na nova sociedade nascente são as antigas posições polares que perdem peso relativo e esses indivíduos[...] passam a formar o elemento mais tipicamente burguês daquela sociedade em mudança [...]" (p. 241). Ou seja, com a introdução do mercado ocorre uma ascensão dos estratos intermediários, estratos esses que, na sociedade brasileira do começo do século XIX, são constituídos basicamente de mestiços. Ao mesmo tempo, ocorre o processo de demonização dos negros, elemento do qual os mestiços tentam se distinguir. Com isso, forma-se a lógica segmentada que explicaria o processo de modernização brasileiro. No nosso caso, instituições como a economia de mercado e o Estado moderno não foram capazes de produzir igualdade mas apenas uma continuação de práticas de segmentação social existentes anteriormente.

Com essa formulação, Jessé Souza articula, na parte final do seu livro, a reinterpretação de Weber por ele proposta na parte inicial com a crítica à explicação do Brasil fornecida por Sérgio Buarque e Raymundo Faoro. De um lado, o argumento analítico sobre o Brasil fornece concretude à análise proposta na primeira parte do livro sobre a relação entre idéias e instituições. A escravidão como instituição cria um estrato de condutores de idéias formado por uma população de mestiços, cujos interesses ideais explicariam a segmentação das formas de assimilação da modernidade pela sociedade brasileira. De outro lado, a crítica ao iberismo em Sérgio Buarque e Raymundo Faoro fornece estofo para a constituição de um marco analítico alternativo de acordo com o qual a continuidade das formas de exclusão criadas pela so- ciedade brasileira é explicada com base nas instituições e nas atitudes públicas e privadas de indivíduos que aqui procuraram constituir um Estado-nação.

O balanço do livro A modernização seletiva é, como já deve ter ficado claro ao leitor desta resenha, altamente positivo. Seu autor foi, de fato, capaz de propor um marco teórico para a análise da formação do Brasil mais sofisticado do que aquele disponível em autores como Buarque de Hollanda e Faoro e, ao mesmo tempo, de fornecer novos elementos teóricos que nos permitem compreender melhor o Brasil. No entanto, parece-me que uma limitação do livro estaria na generalidade do marco analítico proposto. A meu ver, o papel dos mestiços como estratos condutores de uma ética de dualidade e segmentação parece ser mais plausível como um dos elementos analíticos centrais para a explicação do Brasil, em especial, das características do nosso privatismo, do que como elemento explicativo geral sobre a formação brasileira. Parece-me que, se esse marco explica bem o elemento privatista da nossa formação, ele deve ser articulado com uma matriz capaz de explicar também alguns dos elementos da nossa incipiente esfera pública, como a tolerância religiosa, o sincretismo cultural, as formas de solidariedade presentes na nossa matriz cultural e que geraram fenômenos de corte mais igualitário como, por exemplo, o movimento abolicionista no século XIX. Merece ser destacado, também, que o livro se exime de discutir com algumas análises mais recentes sobre o Brasil como, por exemplo, a apresentada por Luiz Werneck Vianna. Apontar tais fatos, porém, de modo algum implica subestimar a enorme contribuição do trabalho de Jessé Souza a uma teoria mais completa e definitiva sobre a formação da sociedade brasileira.

\section{LEONARDO AVRITZER é professor do Departamento de Ciência Política da Faculdade de Filosofia e Ciências Humanas da Universidade Federal de Minas Gerais (UFMG).}




\section{Espaço e cultura na cidade contemporânea}

Antonio A. ARANTES (org.). O espaço da diferença. Campinas, Papirus, 2000. 304 páginas.

Antonio A. ARANTES. Paisagenspaulistanas: transformações do espaço público. Campinas, Editora da Unicamp/Imprensa Oficial, 2000. 190 páginas.

\section{José Guilherme Cantor Magnani}

Nesses dois textos - num dos quais figura como autor e, no outro, como organizador Antonio Augusto Arantes oferece um amplo espectro de temas cujo ponto focal é a cidade contemporânea em sua escala metropolitana e em suas múltiplas dimensões: poder, cultura, cidadania, espaço público. Ambos os livros foram produzidos no contexto dos projetos "Construindo a democracia: cidadania, nação e a experiência urbana contemporânea", financiado pela Fundação Rockfeller, e "Identidades: reconfigurações de cultura e política", com recursos do programa Pronex/Finep.

O primeiro- Oespaço da diferença-éuma coletânea, com doze textos de autores diversos. A metade deles é constituída por traduções de artigos e capítulos de livros já publicados no exterior; outros quatro foram apresentados no simpósio "Espaço e poder nas grandes metrópoles", realizado em Campinas em dezembro de 1996 como parte da agenda dos projetos acima citados, e, completando o volume, temos um artigo baseado em uma dissertação de mestrado e um ensaio inédito.

O leque é amplo e variado. Vai, por exemplo, da reflexão teórica à análise de um original e provocativo experimento: a proposta de um carromoradia para os sem teto, projetado pelo artista Krzysztof Wodiczko. Inclui interpretações da constituição do espaço público em cidades como Nova York, Londres, São Paulo, Rio de Janeiro e análises de paisagens mais específicas como os casos do Harlem, Wall Street e Avenida Paulista. O horizonte percorrido, como se pode perceber, é vasto e esta amplitude evoca a complexidade da dinâmica cultural das grandes cidades, irredutível às costu- meiras categorias e esquemas dicotômicos — centro/periferia, público/privado, tradicional/moderno. A idéia geral da coletânea é justamente mostrar a fluidez dos processos, o movimento dos atores e a ambigüidade das fronteiras e marcos espaciais no contextos das megacidades.

Um dos trabalhos centrais é o da socióloga Sharon Zukin, do Brooklin College e da City University of New York, que comparece com dois textos na coletânea. No primeiro, "Paisagens urbanas pós-modernas: mapeando cultura e poder", Zukin descreve, a partir de uma distinção entre "paisagem" e "vernacular", dois processos de relações entre cultura e poder observáveis no cenário urbano pós-moderno. No que ela classifica de "antigas cidades modernas", como Nova York, Chicago, Londres ou Paris, um desses processos é denominado "enobrecimento" (gentrification) e se caracteriza pela substituição, nos velhos centros decadentes, dos antigos moradores (e seu estilo vernacular) por novos personagens e atividades culturalmente valorizadas. Já em cidades como Los Angeles, Miami, Houston ("novas cidades modernas") o processo de valorização é resultado de outro padrão, como a construção de vastos complexos de consumo explorando a fantasia e o sonho, no estilo Disneyworld.

No segundo texto, apresentado no já referido seminário de 1996, Sharon Zukin retoma essas categorias, fazendo alusões a paisagens da capital paulistana como o bairro da Vila Madalena e a Praça da Sé. Para a autora, a cidade torna-se cada vez mais mercadoria, seja na forma do centro que se enobrece, seja na forma da paisagem que se mercantiliza. "As paisagens urbanas na aurora do século XXI sugerem, paradoxalmente, que a democratização da sociedade é coordenada com uma transformação mais intensa do espaço urbano em mercadoria”, conclui (p. 115).

O tema, em pauta já há algum tempo nos EUA e Europa, faz sentido no caso brasileiro, tendo em vista, por exemplo, a discussão a propósito da restauração do Pelourinho em Salvador, da Praça XV no Rio de Janeiro e, no caso de São Paulo, a campanha da Associação Viva o Centro para revitalização do chamado centro histórico, assim como a polêmica em torno do frustrado projeto de 
construção do megaedificío Maharishi, cujo desenlace, diga-se de passagem, foi recebido com visível alívio por não poucos arquitetos, planejadores e urbanistas.

O segundo livro, Paisagens paulistanas: transformações do espaço público, é dedicado, segundo palavras do autor, ao tema da "construção social do espaço público". Tomando como recorte empírico a cidade de São Paulo, Arantes quer mostrar que, mesmo no caso das cidades globais e das grandes metrópoles, onde parecem imperar a lógica da comunicação midiatizada e a assim chamada "desterritorialização das práticas sociais", o espaço é ainda uma referência significativa. Desde que, claro, seja lido em outra chave, muito diferente daquela que atribui sentidos unívocos, vê fronteiras rígidas e só distingue grupos sociais impermeáveis, em suas identidades fixas. O texto apresenta também um caráter de experimento, buscando uma nova forma de narrar a partir da junção de texto, imagem e design.

O livro é composto de quatro ensaios inéditos e um já publicado, além de fotos, desenhos, e até um roteiro dramatúrgico. Arantes chama seu texto de "polifônico", pelo fato de articular trabalhos e técnicas de naturezas diversas. Cabe notar, contudo, que o termo aqui não está sendo empregado da maneira como aparece no discurso dos antropólogos pós-modernos, em sua crítica ao que denominam de modo de representação "realista", centrado na autoridade e na voz do pesquisador. "Polifônico", para estes últimos, será o texto que incorpora outras vozes, as dos pesquisados e sujeitos dos processos sociais em estudo, considerados também autores do texto etnográfico. " Não é esse, evidentemente, o caso do livro de Arantes nem ele se propunha a isso - , pois, com exceção dos desenhos das crianças, não há nele outras perspectivas e discursos a não ser os do autor e dos seus colaboradores, todos no lado de cá.

Centrado na cidade de São Paulo, Paisagens paulistanas, como seria de se esperar, participa da orientação mais geral já assinalada com relação à

* Ver, a propósito, James Clifford, A experiência etnográfica: Antropologia e Literatura no século $X X$, Rio de Janeiro, Editora da UFRJ, 1998. coletânea organizada pelo autor, aplicada, porém, a um contexto mais particularizado. Arantes recupera inclusive uma perspectiva diacrônica, começando com a São Paulo da passagem dos anos 4050 - das comemorações do IV Centenário - e passando em seguida, até como efeito contrastivo, para o relato dos saques e quebra-quebras de abril de 1983: oficiais ou populares, as celebrações e manifestações "consagram ritualmente configurações particulares do espaço urbano [...] e, ao serem incorporadas à experiência e à memória, fornecem um referencial cênico e cartográfico às práticas sociais" (pp. 90-91).

O "cronotropo" do capítulo IV é o espaço central da São Paulo de hoje, por onde o autor realiza uma caminhada, norteado pela hipótese de que "a experiência urbana contemporânea propicia a formação de uma complexa arquitetura de territórios, lugares e não-lugares, que resulta na formação de configurações espaço-temporais mais efêmeras e híbridas do que os territórios sociais de identidade tematizados pela antropologia clássica." (p. 106). As trocas, conflitos e tensões que vai encontrando espacializam-se numa sucessão e também superposição de territórios, lugares e não-lugares. Daí o título do capítulo, "A guerra dos lugares".

Tomando os dois livros em seu conjunto, é possível perceber, para além da diversidade de recortes, perspectivas e categorias de análise, alguns pontos em comum. O primeiro deles é a perspectiva de que essa diversidade já reflete a própria complexidade dos processos, das práticas sociais e da dinâmica da cidade contemporânea, principalmente em sua escala metropolitana, evocando a fluidez da paisagem, a efemeridade das relações e a trasitividade das fronteiras espaçotemporais por onde transitam seus atores.

O segundo é a urgência de um novo $a p$ proach teórico-metodológico que dê conta dessa nova situação. George Marcus já havia mostrado, no quadro do que denomina uma "etnografia modernista"," a necessidade de superar a perspectiva

** George Marcus, "Identidades passadas, presentes e emergentes: requisitos para etnografias sobre a modernidade no final do século XX ao nível mundial”, Revista de Antropologia, vol. 34, 1991. 
de um enfoque mais tradicional que vincula a formação de identidade a uma determinada localidade; na verdade, diz ele, trata-se de identidades múltiplas e que não podem estar referidas a uma localidade tida como sólida, homogênea, unívoca. Assim, propõe Marcus, é necessário problematizar o espaço, o tempo e até mesmo a perspectiva de análise para que se possa enfrentar os desafios que uma nova conjuntura mundial coloca para o olhar antropológico.

Arantes, em seus trabalhos, busca retomar essa proposta aplicando-a ao contexto mais específico do fenômeno urbano contemporâneo. O recurso a termos como hibridização, porosidades, territorialidades flexiveis, não-lugares, configurações espaço-temporais, paisagens disjuntivas é um indicador que aponta nessa direção, assim como as tentativas de experimentar novos gêneros de registro e narração. A contribuição do olhar etnográfico em diálogo com outros olhares, técnicas de observação e enfoques teóricos, buscando fugir às dicotomias de uma perspectiva reificadora, é uma preocupação constante na reflexão de Arantes e está presente nas duas obras aqui resenhadas.

É preciso, porém, estar atento ao perigo que uma profusão terminológica e a multiplicidade de categorias podem acarretar: quando ainda presas no plano da metáfora, é possível que terminem apenas duplicando, como efeito de caleidoscópio, a heterogeneidade de seu objeto. Um desafio para todos os que têm a cidade contemporânea como tema de estudo é, pois, o de construir modelos analíticos mais econômicos que evitem o risco de se reproduzir, no plano de um discurso interpretativo, a fragmentação pela qual as grandes metrópoles são muitas vezes representadas na mídia, nas artes plásticas, na fotografia e em intervenções artísticas no espaço público.

\section{JOSÉ GUILHERME CANTOR MAGNANI é professor e pesquisador do Departamento de Antropologia da Universidade de São Paulo (USP).}

\section{Sobre a teoria da subjetividade coletiva}

José Maurício DOMINGUES. Criatividade social, subjetividade coletiva e a modernidade brasileira contemporânea. Rio de Janeiro, Contra Capa, 1999. 268 páginas.

\section{Josué Pereira da Silva}

O livro de José Maurício Domingues é formado por sete capítulos mais uma introdução e uma conclusão. Já nas primeiras linhas da introdução o autor anuncia que o eixo de seu trabalho "é a articulação do conceito de subjetividade coletiva com os temas da evolução social e da criatividade social, de um lado, e a modernidade brasileira contemporânea e a mudança social, de outro" (p. 7). Segundo ele, olivro pretende ser "uma contribuição à teoria crítica, concebida de uma forma ampla" ( $\mathrm{p}$. 11), e, ao mesmo tempo, é também "um desdobramento do programa de pesquisa centrado no conceito de subjetividade coletiva" (p. 12). De fato, ao longo de sua argumentação, Domingues deixa claro que os conceitos de subjetividade coletiva e de criatividade social são fundamentais para sua concepção de teoria crítica, que, como foi dito antes, não se limita à chamada Escola de Frankfurt.

Uma apreciação de conjunto indica, por outro lado, que o livro tem dois momentos. O primeiro, constituído pelos quatro capítulos iniciais, é dedicado a uma discussão teórica de natureza mais abstrata, na qual, a partir dos conceitos de subjetividade coletiva e de criatividade social, o autor dialoga criticamente com diversas tradições da teoria social. O segundo momento, correspondendo aos três capítulos restantes, embora também centrado no diálogo crítico com outros autores, está mais voltado para a interpretação de contextos empíricos mais concretos como a modernidade em geral e a modernidade brasileira contemporânea, em particular.

Nas páginas que seguem falarei desses dois momentos. Em primeiro lugar, discutirei cada um deles individualmente; em seguida, tratarei de sua articulação, já que essa articulação é o eixo do livro. 
Sem negar a devida especificidade aos conceitos de criatividade social e de subjetividade coletiva, pode-se afirmar que a argumentação desenvolvida nos quatro primeiros capítulos do livro é bastante semelhante ao que Jeffrey Alexander chamou de "novo movimento teórico" (ver RBCS, n. 4, 1987). Este movimento consiste num conjunto de tentativas, feitas em geral por autores teoricamente orientados, de superar positivamente as velhas, mas sempre presentes, dicotomias que marcaram as ciências sociais, e sobretudo a Sociologia, desde o seu início. Sem entrar no mérito das diversas nomenclaturas utilizadas por diferentes autores para expressar essas dicotomias, é bastante razoável dizer que elas aparecem mais ou menos traduzidas na divisão existente na Sociologia entre programas teóricos que privilegiam, de um lado, os conceitos de ação, agência e processo e, de outro, os que privilegiam os conceitos de função, sistema e estrutura. É claro que as tentativas recentes são no sentido não de afirmar, mas de superar essas dicotomias através de um movimento de síntese, que evite a unilateralidade própria das abordagens puramente acionalistas ou puramente funcionalistas. Essa seria a essência do "novo movimento teórico", segundo Alexander.

Embora a forma como cada autor empreende sua tentativa de resolver o problema assuma traços específicos, pode-se resumir as atuais tentativas de síntese em dois grandes blocos: um que busca a superação das dicotomias mediante uma articulação dialética das duas dimensões, mas ao mesmo tempo mantém a separação analítica entre elas (a teoria crítica de Jürgen Habermas ilustra bem este caso), e outro que procura resolver o mesmo problema por meio da elaboração de um conceito central a partir do qual se busca a articulação das duas dimensões (um bom exemplo aqui é a teoria da estruturação de Anthony Giddens).

A contribuição de Domingues situa-se no interior desse mesmo movimento, aproximandose, porém, mais da tentativa de Giddens que da de Habermas. Digo isto porque, embora o conceito de subjetividade coletiva de Domingues seja diferente do conceito de dualidade da estrutura de Giddens, a mesma intenção subjacente na obra deste último de encontrar um conceito-chave que sintetize dia- leticamente os dois pólos daquilo que, por comodidade, chamarei aqui de ação e estrutura parece estar presente também no trabalho de Domingues.

Um bom exemplo disso é a sua tipologia de subjetividade coletiva, apresentada em seu livro anterior, Sociological theory and collective subjectivity (Londres, Macmillan, 1995). Para Domingues, subjetividade coletiva pode incluir diversas formas de agrupamentos sociais, que variam segundo o nível ou grau de centramento. Os agrupamentos com menor nível de centramento são as redes, seguidas pelas categorias (classes sociais, gêneros e raças ou grupos étnicos), os grupos (comunidade de vizinhança e família), encontros, movimentos sociais, organizações e, finalmente, sociedades. Subjetividade coletiva aparece, portanto, como uma categoria suficientemente abrangente para poder incluir coletividades de natureza tão diferente como, por exemplo, movimento social, organização ou sociedade. Mas não ficou claro para mim de que forma a teoria da subjetividade coletiva se relacionará com as diversas teorias específicas, muitas delas elaboradas para explicar cada uma das coletividades indicadas na tipologia acima. Creio que a teoria da subjetividade coletiva precisa explicitar a forma como lidará com as teorias já existentes sobre classe, gênero, família etc. em termos concretos.

O segundo momento do livro, no qual se postula a concretização da "relação entre teoria e empiria” (p. 144), é menos abstrato que o anterior e está voltado para a discussão da modernidade brasileira contemporânea. Esta é, evidentemente, analisada como parte de um contexto mais amplo, definido pelo autor como modernidade reflexiva. A ênfase de Domingues no caso brasileiro busca realçar a particularidade da modernização no Brasil, sem perder de vista sua inserção no quadro mais amplo de um mundo globalizado. Daí ele poder concluir que o tipo de modernidade vivenciada no Brasil é também uma modernidade reflexiva. Aqui, ao definir sua concepção de modernidade, Domingues aproxima-se mais uma vez das formulações de outros autores, como Ulrich Beck e o próprio Giddens, os quais, como é sabido, também concebem a modernidade contemporânea como modernidade reflexiva. 
Por fim, ao falar da modernidade brasileira, Domingues afirma que "o desafio da teoria sociológica brasileira é precisamente compreender conceitualmente e estimular a investigação empírica dessa teia complexa" (p. 172). Esta afirmação deixa entrever o caráter indicativo e ainda programático de seu empreendimento. Assim, embora seja um empreendimento ousado e promissor, a teoria da subjetividade coletiva ainda precisa passar no teste empírico para se consolidar como um projeto teórico viável. Isto depende, evidentemente, de tempo e de pesquisa, principalmente sobre os diversos tópicos abordados. Mas isto pode perfeitamente ser o passo seguinte de tal empreendimento.

Tudo isso, no entanto, não tira o valor de um livro que atesta o grande domínio de seu autor sobre a literatura pertinente, assim como sua vocação para trabalhar com teoria. Apesar da complexidade de sua temática, o livro, por ser bem escrito, é uma leitura bastante agradável.

\section{JOSUÉ PEREIRA DA SILVA é professor de Sociologia do Instituto de Filosofia e Ciências Humanas da Universidade Estadual de Campinas (Unicamp).}

\section{Sobre as relações entre descentralização $e$ federalismo}

Marta ARRETCHE. Estado federativo e politicas sociais: determinantes da descentralização. Rio de Janeiro/São Paulo, Editora Revan/FAPESP, 2000. 304 páginas.

\section{Gilberto Hochman}

Se tivesse que escolher uma palavra para sintetizar a dinâmica e a direção das políticas sociais no Brasil da década de 1990, esta palavra seria descentralização. Diante das críticas ao caráter centralizador e excludente do Sistema de Proteção Social conformado durante o regime militar, não seria descabido afirmar que a literatura sobre o tema produzida na segunda metade da década de 80 concordaria que, enquanto estratégia e objetivo de reforma do sistema, e do próprio Estado, o processo de descentralização esteve condicionado pelo ambiente político democrático, pelas inovações e regras estabelecidas pela Constituição de 1988, em especial a descentralização fiscal e a extensão de direitos sociais, e pela estrutura socioeconômica do país. Descentralização, a palavra escolhida, rimava com democratização. A intenção ou a decisão de descentralizar tornou-se virtude, um valor político positivo, que passou a ser compartilhada por um expressivo número de legisladores, gestores e analistas de políticas.

Assim sendo, um observador otimista, como grande parte dos analistas do período, identificaria o sinal positivo de vários desses condicionantes e talvez apostasse, em fins da década de 1980, que a descentralização das políticas sociais, entendida como transferência de responsabilidades para as esferas estadual e municipal, seria aprofundada com a transferência de recursos que criariam estruturas e programas em nível subnacional, dando nova feição ao Sistema de Proteção Social Brasileiro. Como este mesmo observador, dez anos depois, reencontraria o seu objeto e como avaliaria a sua aposta?

Complexo, diverso e desigual, responderia eu depois de ler Estado federativo e políticas so- 
ciais. O livro de Marta Arretche, originalmente sua tese de doutorado defendida em 1998 na Unicamp, é uma oportunidade ímpar para um balanço geral do processo de descentralização das políticas sociais pós-Constituição de 1988 e, sobretudo, para uma reflexão sobre a operação dos fatores que determinam esse processo. É uma análise ambiciosa sobre a extensão e as variedades da descentralização que possibilita a apreensão dos determinantes desse processo diversificado e intricado.

Todo este empreendimento está dividido no livro em duas partes. Na primeira, encontramos, no primeiro capítulo, uma discussão crítica da bibliografia sobre descentralização, reforma do Estado e políticas sociais; a identificação das variáveis independentes de natureza estrutural, institucional e política do processo de descentralização em ambiência federativa; e a proposição do modelo analítico tanto para mensurar os "graus de descentralização" do Sistema de Proteção Social nos anos 90, como para avaliar o impacto das variáveis independentes no processo de descentralização nos estados e nas políticas abordadas. No segundo capítulo são apresentados os resultados da aplicação desse modelo, isto é, os determinantes da variação dos "graus de descentralização" entre políticas e entre estados, e o impacto de cada uma das variáveis independentes."

Na segunda parte, um capítulo é dedicado a cada uma das quatro áreas de política social - e aos programas de descentralização nestas áreas escolhidas pela autora para observar o processo de transferência de responsabilidades para estados e municípios, procurando identificar o peso relativo de cada uma das variáveis na explicação dos "graus de descentralização": desenvolvimento urbano (saneamento básico, habitação, instâncias colegiadas estaduais de gestão do FGTS), educação (ensino fundamental e alimentação escolar), assistência social e saúde (habilitação municipal ao SUS e atendimento básico). Nas conclusões, a autora retoma basicamente os argumentos desenvolvidos

* Em artigo já bastante citado, a autora publicou uma versão desses dois capítulos sob o título "Políticas sociais no Brasil: descentralização em um Estado federativo", Revista Brasileira de Ciências Sociais, n. 40, junho de 1999 . no segundo capítulo à luz do detalhamento empírico de sua análise dos programas de descentralização, exposta na parte II.

De modo instigante e muito bem fundamentado teórica e empiricamente, Marta Arretche abre analiticamente a caixa-preta da descentralização e mostra que, se esta foi facilitada pelas transformações políticas e institucionais experimentadas pelo Estado e pela sociedade no Brasil dos anos 80 e dificultada pela crise econômica do início dos anos 90, o seu processo de implementação não foi, ou melhor, não é espontâneo, unicausal, linear e homogêneo, e muito menos o são seus resultados. Porém, ao revelar a heterogeneidade do processo de reforma das políticas sociais nos anos 90 e seus múltiplos condicionantes, Arretche não pretende caracterizá-lo como caótico e indeterminado, mas apresentar ao leitor uma surpreendente inteligibilidade.

Por que São Paulo, o estado mais rico da Federação, tem níveis de descentralização mais baixos que o Ceará, estado com bem menos recursos em uma região pobre do país que tem níveis equivalentes ao Paraná, mais rico e situado em uma das regiões mais prósperas? Por que os programas de descentralização do ensino fundamental obtiveram sucesso e o mesmo não ocorreu com a habitação? Por que numa mesma área de política como desenvolvimento urbano alguns programas foram bem-sucedidos e outros não? Para formular estas perguntas e dar respostas consistentes, Arretche desenvolve sua investigação a partir de um modelo de análise que incorpora como elemento central o fortalecimento das bases federativas do Estado brasileiro pós-1988, isto é, a recuperação da autonomia política dos níveis subnacionais de governo. Este modelo pretende revelar, e mensurar, as variações na extensão do processo de transferência de atribuições. Variações não apenas entre políticas sociais como também entre as unidades federativas. Além disso, identifica as variáveis consideradas determinantes no processo de descentralização, ou que expliquem cada uma dessas variações.

A autora selecionou uma amostra diversificada de estados e de políticas sociais na qual se identificasse a presença ou a ausência de ações 
intencionais de transferência de competências e responsabilidade e, assim, se pudesse observar o comportamento dos principais determinantes da descentralização, seja estadualização ou municipalização. A variável dependente, descentralização de uma política, tornou-se mensurável por "graus de descentralização", correspondendo a diferenças entre estados no que diz respeito à taxa de adesão municipal a um determinado programa, e de participação municipal na provisão de um bem ou serviço, ou, em casos de estadualização, à presença de indicadores que revelem o surgimento de condições para uma gestão autônoma de uma política.

As políticas escolhidas permitiriam avaliar fatores institucionais e estratégias de indução e foram analisadas a partir de programas específicos: municipalização dos serviços de saneamento básico; existência de Sistemas Estaduais de Habitação; programa de criação de instâncias colegiadas estaduais para a distribuição dos recursos do FGTS; municipalização das redes de ensino fundamental; municipalização da merenda escolar; municipalização da política de assistência social; processo de habilitação municipal ao Sistema Único de Saúde e municipalização das consultas médicas. Para cada programa foram identificados "atributos institucionais" ou a presença/ausência de políticas ativas de descentralização e os níveis de governo envolvidos; elaborou-se um indicador de descentralização pertinente para expressar o comprometimento institucional de um dado nível de governo em assumir a sua gestão; foram estabelecidos critérios para se identificar o grau de descentralização de cada programa (baixo, médio e alto) (pp. 270-272).

A escolha dos estados recaiu sobre São Paulo, Rio Grande do Sul, Paraná, Ceará, Pernambuco e Bahia e é justificada pela possibilidade de comparar estados, regiões (Sul-Sudeste e Nordeste) e estados dentro de uma região, bem como avaliar o peso das condições econômicas, capacidade fiscal e administrativa e cultura cívica em cada estado e região, semelhantes entre Paraná e Rio Grande do Sul e diferentes entre Bahia, Pernambuco e Ceará. A inclusão de São Paulo, o estado mais rico e poderoso da Federação, é crucial pois permite testar mais fortemente o peso das variáveis estrutu- rais e institucionais vis-à-vis as vinculadas à ação política. Essas escolhas possibilitaram a identificação dos variados "graus de descentralização" entre políticas, entre estados, entre programas de uma mesma área de política e programas em um mesmo estado, e do peso das variáveis independentes em sua explicação. Isto ancorado em um enorme esforço de construção de indicadores de descentralização para tornar comparáveis entre si diferentes políticas, programas e estados. Dada a extensão da análise de cada uma das políticas e seus condicionantes, vou me deter no que considero a contribuição original do livro de Arretche, tornando-o uma leitura indispensável.

Ao trazer o federalismo para o centro, Estado federativo e políticas sociais firma o seu ponto analítico mais instigante: a saliência dos fatores de natureza política para explicar o sucesso, o fracasso ou a ausência de ações descentralizadoras. Considerando a organização federativa do Estado brasileiro, em que cada ente é autônomo e soberano, o processo de transferência de atribuições e competências origina-se e convive permanentemente com "barganhas federativas". Adicionando ao federalismo as enormes desigualdades estruturais e administrativas entre seus partícipes e a dimensão territorial do país, processos de reforma desta natureza no federalismo brasileiro pressupõem a presença (intensa ou não) ou a ausência de incentivos federais e estaduais, o consentimento e a adesão de estados e municípios e a capacidade (ou não) de coordenação das políticas entre os níveis de governos, envolvendo sempre intensas negociações.

Este ponto deriva da sistematização que a autora faz, a partir de uma revisão bastante seletiva e cuidadosa da bibliografia sobre o tema, das três ordens de fatores que poderiam elucidar um processo descentralizante da magnitude do brasileiro. Para fins da análise empírica, eles são operacionalizados da seguinte forma: (a) fatores estruturais, leia-se capacidade fiscal e capacidade administrativa; (b) fatores institucionais, no caso o legado das políticas prévias, regras constitucionais e a engenharia operacional inerente à prestação de bens e serviços e (c) fatores vinculados à ação política, isto é, ações indutivas das esferas de governo 
interessadas em transferir responsabilidades e presença de tradição de participação política local, ou cultura cívica.

A inovação deste trabalho é justamente acentuar a relevância das ações políticas positivas na direção da descentralização (coordenação, incentivo, indução, cálculo, escolha, decisão), em especial dos governos estaduais, associando-as decisivamente aos impactos das dimensões estrutural e institucional. Marta Arretche sintetiza esse argumento do seguinte modo: "[...] a capacidade fiscal e administrativa das administrações locais [estados ou municípios] influi no processo de reforma; mas, estas variáveis não são determinantes em si mesmas. Seu peso varia de acordo com os requisitos postos pelos atributos institucionais das políticas que se pretende descentralizar, vale dizer, dos custos operacionais implicados na sua gestão, das dificuldades à transferência de atribuições derivadas do legado das políticas prévias e das prerrogativas legais estabelecidas constitucionalmente. [...] No entanto, estratégias de indução eficientemente desenhadas e implementadas por parte dos níveis de governo interessados nas reformas podem compensar obstáculos à descentralização derivados dos atributos estruturais de estados e municípios ou dos atributos institucionais das políticas." (pp. 73-74).

Portanto, o vínculo do processo de descentralização às características do federalismo brasileiro torna central a ação deliberada e organizada de incentivo à adesão das esferas subnacionais. Os governos locais aderem à descentralização a partir de um cálculo em torno dos custos e benefícios de assumir a gestão de um determinado programa social. Um cálculo no qual são componentes a renda e a capacidade fiscal e administrativa, em geral vistas pela bibliografia como determinantes do sucesso do processo, assim como a engenharia operacional necessária para gerir programas, as determinações constitucionais e o legado das políticas já existentes. Para Arretche, o caráter decisivo das estratégias de indução no processo de descentralização assinalado significa dizer que ações deliberadas e eficientes podem alterar as bases de cálculo das unidades locais, modificando o peso e a importância dos condicionantes estruturais e institucionais. Assim, numa federação constituída por alguns estados e milhares de municípios com baixa capacidade fiscal, administrativa, técnica e política para gerenciar políticas sociais complexas, isto é, com graves déficits estruturais e institucionais, a ação deliberada dos níveis superiores de governo, com uma estrutura de incentivos eficaz, pode remover ou diminuir os obstáculos e tornar positivo o resultado do cálculo.

Nesta estrutura de incentivos, os elementos passíveis de ação governamental seriam as normas constitucionais, as regras de um programa de descentralização e seu modo efetivo de operação, uma vez que a engenharia operacional das políticas e seu legado prévio estão dados para o decisor. Porém, ao encontrar variações entre "graus de descentralização" entre estados, Arretche introduz uma outra variável para explicá-las, uma vez que as três variáveis destacadas acima interfeririam nos processos de descentralização produzindo diferenças entre programas, na medida em que são aplicadas igualmente para todos os entes federativos. O que elucida a diferença entre resultados da descentralização entre estados é "a ação dos executivos federal e/ou estaduais". Esse ponto explicaria, por exemplo, graus superiores de descentralização no Ceará comparado com os demais estados nordestinos e com São Paulo. Assim, ao final, demonstra a autora que o sucesso de uma reforma dessa magnitude depende "decisivamente" da ação deliberada dos governos estaduais e federal nela interessados e o seu alcance depende do cálculo dos governos locais sobre os custos e benefícios de assumir competências e responsabilidades em áreas de política social.

O desafio bem-sucedido de Estadofederativo e politicas sociais foi tornar legível o rendimento explicativo de fatores diferentes e complexos, como estrutura econômica, estrutura político-administrativa, engenharia operacional das políticas, herança das políticas existentes, regras constitucionais, cultura cívica e estratégias de indução, nos resultados diferenciados de programas de transferência de responsabilidades em áreas de política social em uma ordem federativa com as características do Brasil na década de 90. A autora o faz montando um quebra-cabeça no qual cada peça- 
políticas e estados - e suas combinações têm características específicas, mas o resultado final a dinâmica da descentralização do Sistema de Proteção Social Brasileiro - é uma imagem articulada empírica e conceitualmente.

Desse modo, Marta Arretche, além de avaliar uma década de descentralização, apresenta-nos uma chave analítica para a reflexão sobre a sua continuidade, velocidade, direção. Ao indagar sobre a década passada, apresenta um modelo analítico plausível e eficaz para refletirmos sobre as possibilidades futuras da descentralização das políticas sociais no Brasil. Estado federativo e políticas sociais é leitura obrigatória para todo pesquisador, analista ou gestor interessado em políticas públicas, federalismo e reforma do Estado.

\section{GILBERTO HOCHMAN \\ é pesquisador e professor da \\ Casa de Oswaldo Cruz/ \\ Fundação Oswaldo Cruz.}

